\title{
Thrombolysis in Acute Ischemic Stroke
}

\author{
Andrea Luisi, PharmD, BCPS, and Anne L. Hume, PharmD, BCPS
}

Editors' Note: This month we continue the new featureSTEPped Care: An Evidence-Based Approach to Drug Therapy. These articles are designed to provide concise answers to the drug therapy questions that family physicians encounter in their daily practice. The format of the feature will follow the mnemonic STEP: safety (an analysis of adverse effects that patients and providers care about), tolerability (pooled dropout rates from large clinical trials), effectiveness (bow well the drugs work and in what patient population [s]), and price (costs of drug, but also cost-effectiveness of therapy). ${ }^{1}$ Hence, the name STEPped Care.

Since the informatics pioneers at McMaster University introduced evidence-based medicine, ${ }^{2}$ Slawson and Shaughnessy ${ }^{3,4}$ bave brought it to mainstream family medicine education and practice. This feature is designed to further the mission of searching for the truth in medical practice. Autbors will provide information in a structured format that allows the readers to get to the meat of a therapeutic issue in a way that can belp physicians (and patients) make informed decisions. The articles will discourage the use of disease-oriented evidence (DOE) to make treatment decisions. Examples of DOEs include blood pressure lowering, decreases in bemoglobin $A_{l c}$, and so on. We will include studies that provide POEMspatient-oriented evidence that matters (myocardial infarctions, pain, strokes, mortality, etc)-with the goal of offering patients the most practical, appropriate, and scientifically substantiated therapies. Number needed to treat to observe benefit in a single patient will also be included as a way of defining advantages in terms that are relatively easy to understand. ${ }^{5,6}$

At times this effort will be frustrating. Even as vast as the biomedical literature is, it does not always support what clinicians do. We will avoid making conclusions that are not supported by POEMs. Nevertbeless, POEMs sbould be incorporated into clinical practice. The rest is up to the reader. Blending POEMs with rational thought, clinical experience, and importantly, patient preferences can be the essence of the art of medicine.

We bope you will find these articles useful and easy to read. Your comments and suggestions are welcome. You may contact the editors through the editorial office of $7 A B F P$ or on the Internet (bttp://clinic.isu.edu/drugsteps/intro.btml). We bope the articles provide you with useful information that can be applied in everyday practice, and we look forward to your feedback.

Rex W. Force, PharmD, STEPped Care Feature Editor John Geyman, MD, Editor

Fournal of the American Board of Family Practice

\section{References}

1. Shaughnessy AF, Slawson DC, Bennett JH. Separating the wheat from the chaff: identifying fallacies in pharmaceutical promotion. J Gen Intern Med 1994;9:563-8.

2. Evidence-based medicine: a new approach to teaching the practice of medicine. Evidence-Based Medicine Working Group. JAMA 1992;268:2420-5.

3. Slawson DC, Shaughnessy AF, Bennett JH. Becoming a medical information master: feeling good about not knowing everything. J Fam Pract 1994;38:505-13.

4. Shaughnessy AF, Slawson DC, Bennett JH. Becoming an information master: a guidebook to the medical information jungle. J Fam Pract 1994;39:489-99.

5. Laupacis A, Sackett DL, Roberts RS. An assessment of clinically useful measures of the consequences of treatment. $N$ Engl J Med 1988;318:1728-33.

6. Wiffen PJ, Moore RA. Demonstrating effectiveness-the concept of numbers-needed-to-treat. J Clin Pharm Ther 1996;21:23-7.
Stroke is the third leading cause of death in the United States. Although the mortality rate from stroke has decreased during the past 50 years, this trend may be ending. 1 The reasons for the change in stroke mortality are unclear, and many factors, including the aging of the population, might be involved. Medications improving both quality of life

Submitted, revised 26 January 1998.

From the Department of Pharmacy (AL, ALH), University of Rhode Island, Kingston; Eleanor Slater Hospital (AL), Cranston; and the Department of Family Medicine (ALH), Memorial Hospital of Rhode Island, Pawtucket. Address reprint requests to Anne L. Hume, PharmD, Department of Pharmacy Practice, University of Rhode Island, Kingston, RI 02881 . and survival after an acute ischemic stroke are urgently needed.

Thrombolysis was first tested as a treatment for acute ischemic stroke almost 40 years ago. Only 14 randomized, placebo-controlled trials for a total of 3500 patients with acute ischemic stroke have been published. ${ }^{2}$ One study, the National Institute of Neurological Disorders and Stroke (NINDS) trial, showed a statistically significant decrease in poor functional outcome with the use of recombinant tissue plasminogen activator (rt-PA) when given within 3 hours of the onset of acute ischemic stroke. ${ }^{3}$ Based on this study, the Food and Drug Administration approved the use of rt-PA for acute 
Table 1. Bleeding Complications and Mortality in the European Cooperative Acute Stroke Study (ECASS) and the National Institute of Neurological Disorders and Stroke (NINDS) Trial, and Number Needed to Harm (NNH).

\begin{tabular}{|c|c|c|c|c|c|}
\hline Trial & rt-PA Dosage & $\begin{array}{l}\text { Bleeding Complication } \\
\text { and Mortality }\end{array}$ & $\begin{array}{c}\text { Treatment Group } \\
\text { No. (\%) }\end{array}$ & $\begin{array}{c}\text { Placebo Group } \\
\text { No. (\%) }\end{array}$ & $\mathrm{NNH}$ \\
\hline \multirow[t]{3}{*}{ ECASS $^{10}$} & $1.1 \mathrm{mg} / \mathrm{kg}$ & Total hemorrhagic events & $134 / 313(42.8)$ & $113 / 307(36.7)$ & NS \\
\hline & ( $10 \%$ as bolus) & Parenchymal hematoma & $62 / 313(19.8)^{\star}$ & $20 / 307(6.5)$ & 8 \\
\hline & & Total mortality & $69 / 313(22.0)^{\dagger}$ & $48 / 307(15.6)$ & 16 \\
\hline \multirow[t]{3}{*}{ NINDS $^{3 \ddagger}$} & $\begin{array}{l}0.9 \mathrm{mg} / \mathrm{kg} \\
(10 \% \text { as bolus })\end{array}$ & $\begin{array}{l}\text { Symptomatic intracranial } \\
\text { hemorrhage }\end{array}$ & $20 / 312(6.4)^{\star}$ & $2 / 312(0.6)$ & 17 \\
\hline & & $\begin{array}{l}\text { Asymptomatic intracranial } \\
\text { hemorrhage } \$\end{array}$ & $14 / 312(4.5)$ & $9 / 312(2.9)$ & NS \\
\hline & & Total mortality & $54 / 312(17.0)$ & $64 / 312(21.0)$ & NS \\
\hline
\end{tabular}

NNH - number of patients who, if they received rt-PA, would lead to 1 additional patient being harmed compared with those receiving placebo.

" $\mathrm{P}<0.001$ versus placebo.

$+\mathrm{P}=0.04$.

₹All patients, parts 1 and 2.

SWithin 36 hours of treatment.

ischemic stroke. Both the American Heart Association and the American Academy of Neurology have now issued practice guidelines recommending the use of rt-PA. ${ }^{4,5}$ Controversy continues, however, because the evidence supporting its safe use in routine medical practice is limited.

\section{Methods}

A MEDLINE search from January 1966 through November 1997 was performed using the search terms "thrombolytic," "stroke," "mortality," "disability," and "randomized controlled trials." Additional studies were found by examining the references cited in trials involving thrombolysis. Studies were selected if they enrolled at least 100 patients, used computed tomographic (CT) scans to exclude patients with intracerebral hemorrhage, and included patient-oriented evidence that matters (POEMs), such as mortality or disability, as primary outcomes. Older trials using urokinase were excluded, because patients were enrolled up to 30 days after onset of symptoms. ${ }^{6}$ The Australian Streptokinase (ASK) trial, the Multicenter Acute Stroke Trial-Europe (MAST-E), and the Multicenter Acute Stroke Trial-Italy (MAST-I) were not included because they were stopped early as a result of an increased mortality rate among streptokinase-treated patients. No data support the use of streptokinase in the treatment of acute ischemic stroke. ${ }^{7-9}$ As a result, only the NINDS and the European Cooperative Acute Stroke Study (ECASS), which used rt-PA, are discussed in this review.,10
This review will use the STEP approach: safety (an analysis of hemorrhagic complications), tolerability (pooled drop-out rates from the trials), effectiveness (how well rt-PA works in patients with acute ischemic stroke and in what patient populations), and price (costs of the drug; cost effectiveness of the therapy) to review the role of rt-PA in the treatment of acute ischemic stroke.

\section{Safety and Tolerability}

Safety and tolerability outcomes that are relevant to thrombolytic therapy in acute ischemic stroke. are fatal and nonfatal intracranial hemorrhage death, and other adverse events. The incidence of hemorrhage that occurred in NINDS and ECASS is summarized in Table 1. For every 8 patients assigned to rt-PA in the ECASS trial, 1 additional patient would develop a parenchymal hematoma (as compared with placebo). Parenchymal hematoma is usually responsible for clinical deterioration. For every 17 patients assigned to rt-PA in the NINDS trial, 1 additional patient would develop a symptomatic intracranial hemorrhage (as compared with placebo).

Other adverse events were mentioned in the ECASS trial. No difference was found in the occurrence of serious adverse events other than intracranial hemorrhage. Events reported included cardiac arrest, cardiac failure, intracranial hypertension, atrial fibrillation, myocardial infarction, pulmonary embolism, somnolence, pneumonia, respiratory insufficiency, renal failure, and cere- 
Table 2. Instruments Used to Measure Outcome in the European Cooperative Acute Stroke Study (ECASS) and the National Institute of Neurological Disorders and Stroke (NINDS) Trial.

\begin{tabular}{|c|c|c|c|}
\hline Instrument $^{11}$ & What It Measures & Point Range & Examples of Ratings \\
\hline Barthel Index (BI) & $\begin{array}{l}\text { Ability to perform activities of } \\
\text { daily living (ie, eating, bathing, } \\
\text { walking, using the toilet) }\end{array}$ & $0-100$ & No disability $=100$ \\
\hline $\begin{array}{l}\text { Scandinavian Stroke } \\
\text { Scale }\end{array}$ & Neurologic deficit & $0-58$ & $\begin{array}{l}\text { Mild neurologic deficit }>50 \\
\text { No deficit }=58\end{array}$ \\
\hline $\begin{array}{l}\text { Modified Rankin Scale } \\
\text { (RS) }\end{array}$ & $\begin{array}{l}\text { Global clinical impression, } \\
\text { overall function assessment }\end{array}$ & $0-5$ & $\begin{array}{l}\text { No symptoms (total recovery) }=0 \\
\text { Severe disability }=5\end{array}$ \\
\hline Glasgow Outcome Scale & Global assessment of function & $1-5$ & $\begin{array}{l}\text { Good recovery }=1 \\
\text { Moderate disability }=2 \\
\text { Severe disability }=3 \\
\text { Vegetative state }=4 \\
\text { Death }=5\end{array}$ \\
\hline $\begin{array}{l}\text { National Institutes of Health } \\
\text { Stroke Scale (NIHSS) }\end{array}$ & Serial measure of neurologic deficit & $0-42$ & $\begin{array}{l}\text { No deficit }=0 \\
\text { Mild facial paralysis = } 1 \\
\text { Complete right hemiplegia with } \\
\text { aphasia, gaze deviation, visual-field } \\
\text { deficit, dysarthria, and sensory loss }=25\end{array}$ \\
\hline Wald test & $\begin{array}{l}\text { Global test statistic, simultaneously } \\
\text { tests for effect in four outcomes } \\
\text { measures (BI, RS, NHHS, and } \\
\text { Glasgow Outcome Scale) }\end{array}$ & & \\
\hline
\end{tabular}

brovascular disorder..$^{10}$ No other adverse events were mentioned in the NINDS trial, although outcome data were missing on 5 patients. ${ }^{3}$

\section{Effectiveness}

Improved functional status and decreased mortality are the primary efficacy outcomes on trials of thrombolytic therapy in acute ischemic stroke. ECASS and NINDS differed in their study design, including dosages of rt-PA, exclusion criteria,

Table 3. Number Needed to Treat for rt-PA

Versus Placebo.

\begin{tabular}{lcc}
\hline & \multicolumn{2}{c}{ Number Needed to Treat* } \\
\cline { 2 - 3 } Instrument & $\begin{array}{c}\text { ECASS } \\
\text { (90 days) }\end{array}$ & $\begin{array}{c}\text { NINDS, Part 2 } \\
\text { (90 days) }\end{array}$ \\
\hline Barthel Index & NS & 8 \\
Modified Rankin Scale & NS & 8 \\
Scandinavian Stroke Scale & NS & NR \\
National Institutes of Health & & \\
Stroke Scale & NR & 9 \\
Glasgow Outcome Scale & NR & 8
\end{tabular}

*Number of patients who need to receive treatment to prevent a single adverse outcome.

ECASS - European Cooperative Acute Stroke Study. NINDS National Institute of Neurological Disorders and Stroke.

NS - not statistically significant.

NR - not reported. concomitant treatments, evaluation instruments, and time from the onset of the stroke to the receipt of the rt-PA. Table 2 describes the instruments used to assess outcomes in these studies. ${ }^{11}$

\section{European Cooperative Acute Stroke Study (ECASS)}

ECASS enrolled 620 patients who were randomized to treatment with $\mathrm{rt}-\mathrm{PA}(1.1 \mathrm{mg} / \mathrm{kg})$ or placebo within 6 hours after the onset of symptoms. ${ }^{10}$ The median time from stroke onset to treatment was 4.3 hours. A bolus of 10 percent of the total dose was given during the first 1 to $2 \mathrm{~min}$ utes, followed by a 60 -minute infusion of the remaining dose. ECASS excluded concomitant use of heparin and anticoagulants, but permitted aspirin. ${ }^{10}$ Functional and clinical outcomes were defined by changes in the Barthel Index (activities of daily living) and the modified Rankin Scale (global functional assessment) at 90 days. Mortality and neurologic deficit were measured at 30 days with the Scandinavian Stroke Scale. ${ }^{11}$ The following summarizes the results from the intention-to-treat analysis of the data (Table 3).

The rt-PA and placebo groups were similar in the change in ability to perform activities of daily living $(P=0.99)$. There was no difference between the rt-PA and placebo groups functionally $(P=$ $0.41)$ or neurologically $(P=0.54)$ at 90 days. The mortality rate was significantly higher in the rt-PA 
Table 4. Contraindications to the Use of rt-PA in Acute Ischemic Stroke.

CT scan reveals intracranial hemorrhage

Initiation of treatment more than 3 hours after onset of symptoms

Previous intracranial hemorrhage

Previous stroke or serious head trauma within 3 months

Rapidly improving or minor symptoms

Symptoms suggestive of subarachnoid hemorrhage

Major surgery within 14 days

Urinary or gastrointestinal hemorrhage within 21 days

Arterial puncture at noncompressible site within 7 days

Seizure at stroke onset

Elevated partial thromboplastin time (PTT)

Elevated prothrombin time $>15$ seconds

Platelet count $<100,000 / \mathrm{L}$

Use of oral anticoagulants or heparin within 48 hours with elevated PTT

Serum glucose $<50 \mathrm{mg} / \mathrm{dL}$ or $>400 \mathrm{mg} / \mathrm{dL}$

Systolic blood pressure $>185 \mathrm{mmHg}$ or diastolic blood pressure $>110 \mathrm{mmHg}$ at time of treatment or aggressive treatment to reduce blood pressure needed to reach specified limits

group at 90 days (22.4 versus 15.8 percent for placebo, $P=0.04)$. There were significantly more hemorrhage-related deaths in the rt-PA group (6.3 percent) versus the placebo group (2.4 percent), $P$ $=0.02$. Functional outcome data for those with a hemorrhagic event versus those without were not presented.

In evaluating ECASS, important considerations are the analyses of the data and the interpretation of CT findings. ${ }^{12,13}$ The intention-to-treat analyses of ECASS did not show a benefit with rt-PA compared with placebo for the primary endpoints of the Barthel Index and modified Rankin Scale at 90 days. Exclusion of the 109 patients who were considered to have a protocol violation resulted in a target population that, when analyzed again, showed a significant benefit with rt-PA as measured by the Rankin Scale. In the intention-totreat analysis, ECASS reported a statistically significant increase in mortality with rt-PA that was subsequently reduced in the target population analysis. Most of the protocol violations were due to CT exclusions, with 66 patients removed from the target population because reinterpretation of their CT scans showed the presence of "early infarct signs. ${ }^{12}$

The data reported in ECASS from the target population might not be as reflective of the pa- tients that physicians commonly see as were the data from the intention-to-treat population. The critical issue for practice is whether the second analysis essentially turned a negative study into a positive one. In addition, and perhaps most important, is the issue that the radiologists involved in ECASS had been specifically trained in the protocol, and yet a large percentage of patients were excluded in the target population analysis because of initial misreading of CT scans. How well would an experienced radiologist at a community hospital do, where reinterpretation of the CT scan before administration of the drug might not be possible? These issues raise serious concerns about the use of this study for recommendations about $\mathrm{rt}-\mathrm{PA}$ in routine medical practice.

\section{National Institute of Neurological Disorders and Stroke (NINDS) trial}

The NINDS trial was divided into two parts. Each was essentially an independent study, but the same protocol was followed in both parts. ${ }^{3}$ In both studies patients were randomized to receive either intravenous $\mathrm{rt}-\mathrm{PA}(0.9 \mathrm{mg} / \mathrm{kg})$ or placebo within 3 hours of the onset of symptoms. Ten percent of the dose was given as a bolus, with the rest of the dose given as an 1-hour infusion. The NINDS trial restricted the use of any anticoagulant, antiplatelet, or heparin therapy for 24 hours. ${ }^{3}$ The exclusions for this trial are listed in Table 4.

The first part of the trial examined the resolution of neurologic deficits within 24 hours of the onset of symptoms $(n=291)$. The second part evaluated clinical outcomes at 3 months $(n=333)$, using the Wald test, which combines results from four scales: Barthel Index, modified Rankin Scale, Glasgow Outcome Scale, and the National Institute of Health Stroke Scale. A favorable outcome was defined based on specific values for each of the four indexes, reflecting minimal or no disability, such as mild facial droop or slight arm drift.

Improvement in neurologic status at 24 hours was not different between the rt-PA and placebo groups $(P=0.21)$. The odds ratio for a favorable outcome with rt-PA at 90 days, determined by the Wald test, was 1.7 (95 percent confidence interval [CI], 1.2-2.6). Patients who received rt-PA were 30 percent more likely to have minimal or no disability at 3 months $(P=0.026)$. Mortality rates were 17 percent and 21 percent in the rt-PA and placebo groups, respectively $(P=0.30)$. Sixty-one 
Table 5. Drug STEPS Quick Read.

\begin{tabular}{|c|c|}
\hline \multirow[t]{2}{*}{$\begin{array}{l}\text { Safety and } \\
\text { Tolerability }\end{array}$} & $\begin{array}{l}\text { ECASS }{ }^{10} \text {-more patients who received rt-PA } \\
\text { died versus placebo }(\mathrm{p}=0.04) \text {. Significantly } \\
\text { more parenchymal hematomas occurred in } \\
\text { rt-PA group versus placebo }(19.4 \% \text { versus } \\
6.8 \%, P<0.001)\end{array}$ \\
\hline & $\begin{array}{l}\text { NINDS }^{3}-\text { rt-PA was associated with } \\
\text { significantly higher number of symptomatic } \\
\text { intracranial hemorrhage compared with } \\
\text { placebo }(6.4 \% \text { versus } 0.6 \%, P<0.001) \text {. }\end{array}$ \\
\hline \multirow[t]{2}{*}{ Effectiveness } & $\begin{array}{l}\text { NINDS }{ }^{3} \text {-rt-PA did not result in } \\
\text { decrease in mortality from acute ischemic } \\
\text { stroke, but functional outcome was shown } \\
\text { to improve. }\end{array}$ \\
\hline & $\begin{array}{l}\text { ECASS }{ }^{10} \text {-rt-PA increased mortality and } \\
\text { did not improve functional outcome. }\end{array}$ \\
\hline Price & $\begin{array}{l}\text { One dose of rt-PA costs } \$ 2750 \text {; however, in } \\
\text { the context of total cost of ischemic strokes, } \\
\text { this cost is small. }\end{array}$ \\
\hline Summary & $\begin{array}{l}\text { If patients are admitted within } 3 \text { hours of } \\
\text { symptom onset, NINDS exclusion criteria } \\
\text { are not present, and CT scanning has ruled } \\
\text { out intracranial hemorrhage, patients can } \\
\text { have better functional status after stroke. Few } \\
\text { patients who receive rt-PA are likely to meet } \\
\text { these conditions. }\end{array}$ \\
\hline
\end{tabular}

percent of the patients with symptomatic hemorrhage had died at 3 months. Table 3 summarizes these results with number-needed-to-treat data. Functional outcome data comparing patients with intracranial hemorrhage versus those without were not presented. Current recommendations for the use of rt-PA have been based on the strengths of this study.

\section{Implications for Practice}

For the practicing physician, the most important question remains, Can the benefits reported in NINDS be safely achieved in the hospital to which I admit my patients with acute ischemic stroke? In general, if rt-PA is to be used safely based on the NINDS, three specific components of care in the form of a stroke team should be present. ${ }^{1+}$ First, a physician with appropriate expertise to diagnose the stroke must be available. Although attention has been focused on whether a given hospital has an organized stroke unit or neurologic intensive care unit, many of the institutions involved with NINDS had neither. ${ }^{15}$ The second factor is the 24-hour availability of a facility to provide CT scanning. As mentioned previously, 11 percent of scans in ECASS were later reinterpreted to have "early infarct signs" suggesting hemorrhagic transformation. The third basic consideration is that the facility have the capability to manage intracra- nial hemorrhage and other complications of thrombolytic therapy.

Do any patient-related factors predict either a good or bad (ie, intracranial hemorrhage or lack of benefit) outcome with rt-PA? Using information from the NINDS trial, two subsequent analyses failed to discover factors that would be clinically useful in predicting these outcomes consistently. ${ }^{16,17}$ Patients who were at higher risk for an adverse event were just as likely to receive benefits from treatment. For example, older patients with higher baseline National Institutes of Health Stroke Scale (NIHSS) scores were more likely to have a poor outcome, regardless of treatment. These patients, however, also benefited from treatment, as did patients with moderate deficits at baseline. Although the second analysis found that a severe neurologic deficit and brain edema (or mass effect) on CT scan at baseline were associated with a higher risk of intracranial hemorrhage, these variables predicted its occurrence only 57 percent of the time. Patients with these characteristics who received $\mathrm{rt}-\mathrm{PA}$ were also more likely to have a favorable outcome than patients in the placebo group with these characteristics.

Another potential confounding variable is the use of aspirin in acute ischemic stroke. Aspirin is the current standard of care based on the International Stroke Treatment (IST) ${ }^{18}$ and the Chinese Acute Stroke Treatment (CAST) ${ }^{19}$ trials. Aspirin was shown to decrease slightly the combined endpoints of death and recurrent stroke without increasing hemorrhagic infarctions. Because ECASS and NINDS did not use aspirin to any appreciable extent, and IST and CAST did not use rt-PA, it is difficult to sort out the treatment effects of these medications in 1998.

How do physicians resolve the conflict between the differing results of ECASS and NINDS? The answer to this question is not known; however, one might postulate that more patients who received rt-PA died in ECASS because of the greater dose of $\mathrm{rt}-\mathrm{PA}$ (1.1 $\mathrm{mg} / \mathrm{kg}$ versus $0.9 \mathrm{mg} / \mathrm{kg}$ in NINDS), longer time to treatment ( 6 hours versus 3 hours), or differences in CT technology between Europe and the United States.

Perhaps the most important consideration, however, is the recognition that most stroke patients will not be eligible for rt-PA either because they will have had symptoms for longer than 3 hours (or upon arising in the morning) or they will 
have an exclusion according to the NINDS criteria (Table 4). Each hospital participating in NINDS enrolled on average only 2 to 5 patients per year.

If the appropriate conditions are met, intravenous rt-PA in a dosage of $0.9 \mathrm{mg} / \mathrm{kg}$ (up to a maximum of $90 \mathrm{mg}$ ) has been shown to have potential benefits. The rt-PA should be given with 10 percent of the dose administered as a bolus followed by a 60 -minute infusion within 3 hours of the onset of symptoms. In summarizing the safety and effectiveness of rt-PA, patients must seek help early, their condition must be carefully evaluated, they should receive a CT scan to rule out hemorrhage, and they should receive the drug within a 3hour period.

\section{Price}

In the context of the total costs associated with treatment in the intensive care unit and subsequent rehabilitation, rt-PA costs $(\$ 2750)$ are negligible. While several cost-effectiveness and quality-of-life models have been published on the use of thrombolytic therapy in acute myocardial infarction, similar information on the use of rt-PA for acute ischemic stroke is not currently available. Improvements in the functional status of stroke survivors should benefit the person's quality of life and potentially decrease nursing home costs; however, data specifically with rt-PA have not been published. Similarly, several studies have shown that patients at risk for a stroke consider a severe stroke with disabling hemiplegia, confusion, or global aphasia to be equal to or worse than death. ${ }^{20}$ If $\mathrm{rt}$ PA can be used safely and effectively to improve functional status, one intuitively suspects that quality of life should be improved.

\section{Summary}

The administration of rt-PA to patients with acute ischemic stroke can result in improved functional outcomes. The safe and effective use of $\mathrm{rt}-\mathrm{PA}$ in routine medical practice requires that patients seek help early, have a well-defined onset of their symptoms, be carefully examined for contraindications to $\mathrm{rt}-\mathrm{PA}$, receive a CT scan and interpretation to exclude hemorrhage, and receive the drug within a 3-hour period (Table 5).

Intravenous rt-PA is given in a dosage of $0.9 \mathrm{mg} / \mathrm{kg}$ (up to a maximum of $90 \mathrm{mg}$ ) with 10 percent of the dose administered as a bolus followed by a 60 -minute infusion within 3 hours of the onset of symptoms. If these conditions cannot be achieved, the drug should not be administered. Although most patients will not meet the criteria of the NINDS trial, rt-PA is an important advance in the treatment of acute ischemic stroke.

\section{References}

1. Gillum RF, Sempos CT. The end of the long-term decline in stroke mortality in the United States? Stroke 1997;28:1527-9.

2. Wardlaw JM, Warlow CP, Counsell C. Systematic review of evidence on thrombolytic therapy for acute ischaemic stroke. Lancet 1997;350:607-14.

3. Tissue plasminogen activator for acute ischemic stroke. The National Institute of Neurological Disorders and Stroke rt-PA Stroke Study Group. N Engl J Med 1995;333:1581-7.

4. Adams HP Jr, Brott TG, Furlan AJ, Gomez CR, Grotta J, Helgason CM, et al. Guidelines for thrombolytic therapy for acute stroke: a supplement to the guidelines for the management of patients with acute ischemic stroke. A statement for healthcare professionals from a Special Writing Group of the Stroke Council, American Heart Association. Stroke 1996;27:1711-8.

5. Practice advisory: thrombolytic therapy for acute ischemic stroke-summary statement. Report of the Quality Standards Subcommittee of the American Academy of Neurology. Neurology 1996;47:835-9.

6. Wardlaw JM, Warlow CP. Thrombolysis in acute ischemic stroke: does it work? Stroke 1992;23:1826-39.

7. Donnan GA, Davis SM, Chambers BR, Gates PC, Hankey GJ, McNeil JJ, et al. Streptokinase for acute ischemic stroke with relationship to time of administration. Australian Streptokinase (ASK) Trial Study Group. JAMA 1996;276:961-6.

8. Thrombolytic therapy with streptokinase in acute ischemic stroke. The Multicenter Acute Stroke Trial-Europe Study Group. N Engl J Med 1996; 335:145-50.

9. Randomised controlled trial of streptokinase, aspirin, and combination of both in treatment of acute ischaemic stroke. Multicenter Acute Stroke Trial Italy (MAST-I) Group. Lancet 1995;346:1509-14.

10. Hacke $W$, Kaste $M$, Fleschi $C$, Toni D, Lesaffre E, von Kummer R, et al. Intravenous thrombolysis with recombinant tissue plasminogen activator for acute hemispheric stroke. The European Cooperative Acute Stroke Study (ECASS). JAMA 1995;274: 1017-25.

11. Lyden PD, Lau GT. A critical appraisal of stroke evaluation and rating scales. Stroke 1991;22:1345-52.

12. Wyer PC, Osborn HH. Recombinant tissue plasminogen activator: in my community hospital $\mathrm{ED}$, will early administration of rt-PA to patients with the initial diagnosis of acute ischemic stroke reduce mortality and disability? Ann Emerg Med 1997;30: 629-38.

13. Kasner SE, Grotta JC. Emergency identification 
and treatment of acute ischemic stroke. Ann Emerg Med 1997;30:642-53.

14. Hachinski V. Thrombolysis in stroke: between the promise and the peril. JAMA 1996;276:995-6.

15. A systems approach to immediate evaluation and management of hyperacute stroke. Experience at eight centers and implications for community practice and patient care. The National Institute of Neurological Disorders and Stroke (NINDS) rt-PA Stroke Study Group. Stroke 1997;28:1530-40.

16. Generalized efficacy of $t-P A$ for acute stroke. Subgroup analysis of the NINDS t-PA Stroke Trial. Stroke 1997;28:2119-25.

17. Intracerebral hemorrhage after intravenous $t-P A$ therapy for ischemic stroke. The NINDS $t-P A$ Stroke Study Group. Stroke 1997;28:2109-18.

18. The International Stroke Trial (IST): a randomised trial of aspirin, subcutaneous heparin, both, or neither among 19435 patients with acute ischaemic stroke. International Stroke Trial Collaborative Group. Lancet 1997;349:1569-81.

19. CAST: randomized placebo-controlled trial of early aspirin use in 20,000 patients with acute ischaemic stroke. CAST (Chinese Acute Stroke Trial) Collaborative Group. Lancet 1997;349:1641-9.

20. Solomon NA, Glick HA, Russo CJ, Lee J, Schulman KA. Patient preferences for stroke outcomes. Stroke 1994;25:1721-5. 